\title{
Laser Welding in Orthodontics: A Review Study
}

\section{Smarika Jain ${ }^{1}$, Pavan Kumar Vibhute ${ }^{2}$, Chetan Patil ${ }^{3}$, Vinay Umale ${ }^{4}$, Rohit Kulshrestha ${ }^{5 *}$, Kshama Chandurkar ${ }^{6}$}

${ }^{1}$ PG Student, Department of Orthodontics and Dentofacial Orthopedics, Yogita Dental College, Khed, Maharashtra, India.

${ }^{2}$ Professor and Head, Department of Orthodontics and Dentofacial Orthopedics, Yogita Dental College, Khed, Maharashtra, India.

${ }^{3}$ Reader, Department of Orthodontics and Dentofacial Orthopedics, Yogita Dental College, Khed, Maharashtra, India.

${ }^{4}$ Senior Lecturer, Department of Orthodontics and Dentofacial Orthopedics, Yogita Dental College, Khed, Maharashtra, India.

${ }^{5}$ Senior Lecturer, Department of Orthodontics and Dentofacial Orthopedics Terna Dental College, Navi Mumbai Maharashtra India.

${ }^{6}$ Senior Lecturer, Department of Oral Pathology, Yogita Dental College, Khed, Maharashtra, India.

*Corresponding Author: Rohit Kulshrestha, Department of Orthodontics and Dentofacial Orthopedics Terna Dental College, Navi Mumbai, Maharashtra India; Email: kulrohit@gmail.com

Received Date: 08-04-2020; Accepted Date: 16-04-2020; Published Date: 23-04-2020

Copyright $^{\oplus} 2020$ by Kulshrestha R, et al. All rights reserved. This is an open access article distributed under the terms of the Creative Commons Attribution License, which permits unrestricted use, distribution, and reproduction in any medium, provided the original author and source are credited.

Abstract
Since its initial development, the laser has been hailed as a potentially useful welding tool for
a variety of applications. The scope for technical and commercial laser welding applications
has increased greatly since the development of multi-kilowatt $\mathrm{CO}_{2}$ lasers around 1970. The
laser's capability of generating a power density greater than 106 watts/cm ${ }^{2}$ is a primary factor
in establishing its potential for welding. Numerous experiments have shown that the high-
quality precision weld joints are permitted by lasers which are rivaled only by electron beam.
By reviewing recent work in the field, this article will present the state of the art of laser
welding. This paper attempts to give an insight into the laser welding and its principle and types
of lasers used for orthodontic purposes, types of dental alloys used by the orthodontist, and
effect of various laser parameters. The literature review has made this apparent that laser
assisted orthodontic welding will continue to grow and will become an unparalleled technology
for orthodontic arena. The laser thus offers an easily maneuvered, chemically clean, high-
Kulshrestha R / Volume 1; Issue 1 (2020) | JDHOR-1(1)-001 | Review Article
Citation: Jain S, Vibhute PK, Patil C, Umale V, Kulshrestha R and Chandurkar K. Laser Welding in
Orthodontics: A Review Study. J Dental Health Oral Res. 2020;1(1):1-14.
DOI: http://dx.doi.org/10.46889/JDHOR.2020.1101


intensity, atmospheric welding process producing deep-penetration welds (aspect ratio greater than 1:1) with narrow Heat Affected Zone (HAZ) and subsequent low distortion.

\section{Keywords}

Dental Alloys; Laser Welding; Orthodontics

\section{Introduction}

In orthodontics, joining the same alloys or metal is prerequisite. For joining in the past different natures of thermal joining techniques have been used. The commonest are soldering, resistance welding, plasma welding and single pulse tungsten inert gas welding. However, these days laser welding using an Nd:YAG laser becomes very feasible as the joining technique for the dentist. Some criteria are set by standard DIN EN 29333 such as stability up to $350 \mathrm{MPa}$, free of macro-defects, and being corrosion resistant, the process through which the joints are connected should satisfy this criteria. An overview of different joining techniques is given in Table 1. For joining dental alloys tungsten inert gas and plasma arc welding are also used with the help of non-consumable electrode. Advantage is that it can offer high quality joints with better finishing. Disadvantage is, these techniques suffer due to heat affected zones profoundly. Moreover, resistance welding that offers joints with no heat affected zone. It can also be useful for joining different materials by using the heat coming from electrical resistance of materials; but overlapping joints is needed in this technique. On the other hand, all the metals can be welded using laser welding including Ti alloys [1-3].

\begin{tabular}{|c|c|c|c|c|c|c|}
\hline Method & $\begin{array}{c}\text { Torch } \\
\text { Soldering }\end{array}$ & $\begin{array}{c}\text { Post ( Ceramic } \\
\text { Furnace) or } \\
\text { Infrared } \\
\text { Soldering }\end{array}$ & $\begin{array}{c}\text { Spot } \\
\text { Welding }\end{array}$ & $\begin{array}{c}\text { Plasma } \\
\text { Welding }\end{array}$ & $\begin{array}{c}\text { Laser } \\
\text { Welding }\end{array}$ & $\begin{array}{c}\text { Tungsten } \\
\text { Inert Gas } \\
\text { (TIG) }\end{array}$ \\
\hline $\begin{array}{c}\text { Equipment } \\
\text { expenditure }\end{array}$ & Small & Moderate & Small & Moderate & High & Moderate \\
\hline $\begin{array}{c}\text { Application } \\
\text { depth, versatility }\end{array}$ & High & High & Small & Medium & High & High \\
\hline $\begin{array}{c}\text { Educational } \\
\text { Prerequisite }\end{array}$ & Moderate & Moderate & Small & Medium & Medium & Medium \\
\hline Biocompatibility & Small & Small & Good & Moderate & Good & Good \\
\hline $\begin{array}{c}\text { Haet Affected } \\
\text { Zone }\end{array}$ & Large & Large & Small & Medium & Very & Very Small \\
\end{tabular}

Table 1: Evaluation of different joining methods. 
In addition, other benefits are also offered by laser welding such as high mechanical strength, reduced distortion due to a narrow heat affected zone, least contamination with oxide free part, faster process time, corrosion resistant joint, and no galvanic effect due to welding without third material. In terms of biocompatibility, laser welded fibroblast joints proved to be superior as compared to a soldered one. Laser welded joint being $100 \%$ hypoallergenic, non-reactive and insoluble in oral environment has been reported.

Lasers was first invented by Theodre Maimann in 1960 and Gordon and Smith in 1970 conducted its first laboratory test. Since then lasers have come a long way towards satisfying the technological needs that rises along its way [1].

This paper attempts to provide a comprehensive review of laser welding of orthodontic alloys including underpinning knowledge of laser technology, associated limitations and future trends.

\section{Rationale of Laser Welding}

Despite its known limitations soldering (brazing) which is the commonest conventional method of connecting dental alloys is still being practiced. Soldering is relatively complex and timeconsuming. It requires multiple preparation steps, with each step a source of distortion or misfit. Third low fusing alloy (solder) with a different chemical composition and a melting point lower than the parent alloy is also required. Finally soldering is highly technique sensitive [3-5].

On the contrary, the advantages of laser beam welding over the conventional procedures are:

1. Less distortion involved due to the narrow Heat Affected Zone (HAZ) producing narrow welds with controlled bead size.

2. Welding is done faster with high productivity, minimum contamination with oxide free and polished seams and high mechanical strength of the welded seams.

3. The amount of time consumed is considerably reduced as all the welding is done directly on the master cast.

4. Multiple preparation steps are not involved reducing the distortion and thereby resulting in a precise fit.

5. No additional metal or solder is required.

6. Galvanic effect is eliminated as the weld is with the parent metal (self-welding).

7. The joint formed is corrosion resistant.

8. Welding very close to acrylic resin or ceramic is also possible with no physical cracking or color damage. 
9. All metals particularly titanium alloys can be laser welded.

10. A homogenous structure with a high mechanical strength which is consistent with that of the parent alloy can be achieved.

11. Welding titanium occurs in an argon gas environment providing a biocompatible and corrosion free joint.

12. The risk of warping is eliminated as the weld affected area is of limited range of approximately $0.25-2 \mathrm{~mm}$.

13. A superior fibroblast biocompatibility with welded joints was found in the study done by solmi et al. on the interaction of fibroblast with soldered and welded joints. 100\% hypoallergenic with the weld remaining non-reactive and insoluble in oral fluids have been found with laser welded joint.

\section{State of the Art of Laser Technology}

Technology of lasers, from the first demonstration given by Maiman in 1960, is almost near to reach a 60 year old life. This technology, following several steps of improvements, became a fundamental part of the modern life [6]. Lasers have assumed a tremendous impact in a large number of different fields such as: science, engineering, technology and medicine. Their importance extends from basic research to mundane technology. Laser devices can be found everywhere, ranging from consumer devices like CD players, laser printers and tag scanners, to industrial applications like welding, drilling, cutting and texturing.

\section{Principle of Laser}

The word LASER simply means Light Amplification by Stimulated Emission of Radiation. It gives a basic idea of principles on which laser devices work, i.e., the generation of a monochromatic, coherent, collimated and intense beam of light. Every device capable of producing a laser radiation, the term laser is associated with that for extension, Fig. 1. According to laser principles, all laser devices should be composed of three fundamental parts: an optical active material, an optical feedback and an energy supply [7-10].

An optical active material is present in the core of laser device. This material is capable of absorbing the electromagnetic radiation, represented by photons, at a particular wavelength, thus promoting the atoms of the material to a higher energy state. The material can re-emit photons in a different wavelength after that. 
(a)

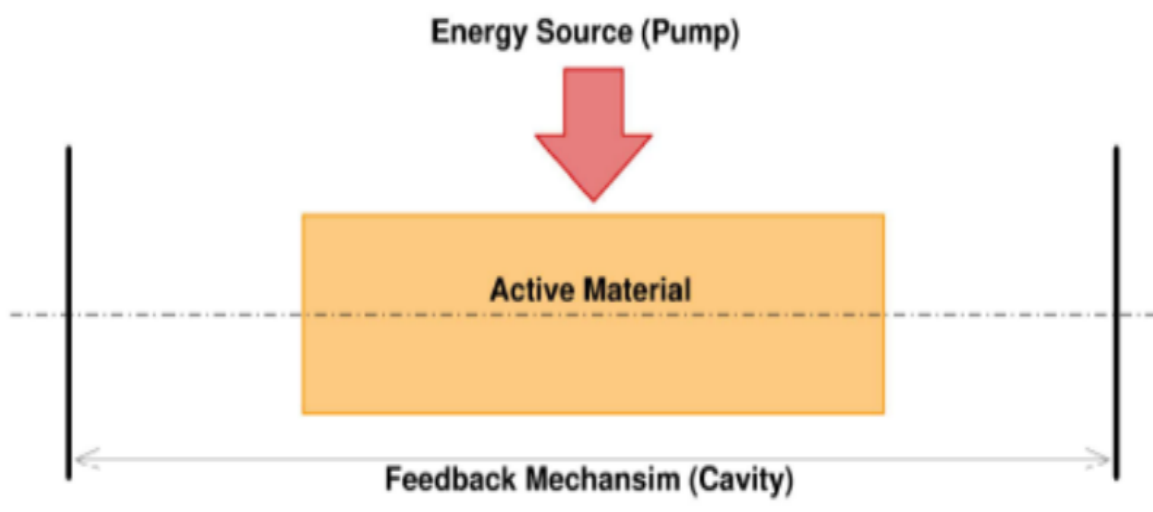

(b)
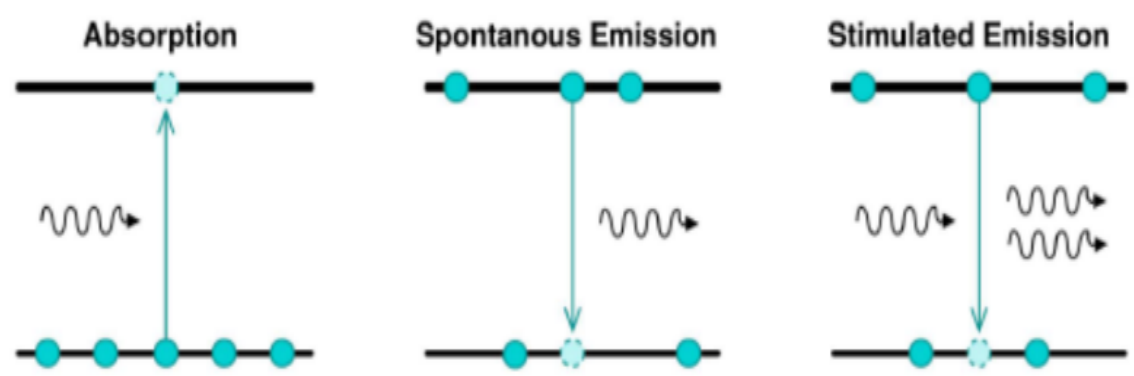

(c)
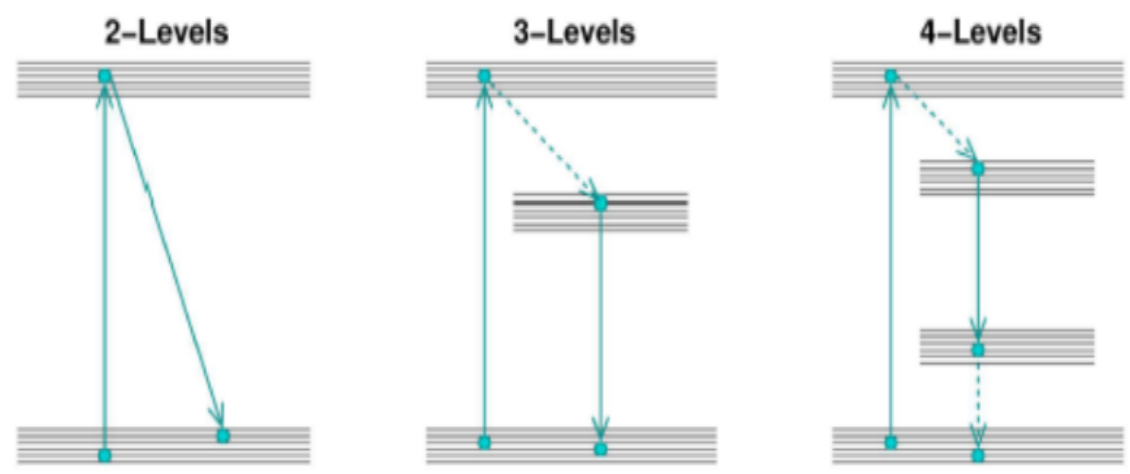

Figure 1: (a) Schematic of a laser device, where an active medium is surrounded by a cavity, giving source; (b) Mechanism of light; (c) In real optical media, optical amplification can pass through several energy bands, and some of these passages are non-radiative (dashed line).

Laser devices are classified according to their active material. Thus, lasers can be divided in these main families, with their pros and cons: 


\section{a) Semiconductor Lasers (Diode Laser):}

Pros: It is obtained using a p-n junction, pumping with an electrical current. Semiconductor laser are versatile in nature. They can be found in several wavelengths covering the visible spectrum, the near-Infrared (IR) and the mid-IR are some examples. For industrial application the emission power can vary from a few milliwatts to several watts [11-13].

Cons: Poor quality of beam is emitted by semiconductor lasers; for this reason, it is common to use this kind of laser as a pump.

\section{b) Gas Lasers:}

The emitted beam quality is very high. The main characteristic feature of gas lasers is to efficiency in emission where the other types of lasers have a poor emission. $\mathrm{CO}_{2}$ laser suitable for macro-machining operation, welding and cutting due to its emission quality [14].

\section{c) Solid State Lasers:}

The gain media in these lasers are crystals or glasses which are properly doped with rare earth or transition metal ions. Nd:YAG, Nd:glass, Yb:YAG, Yb:glass, Ti:shapphire, Cr:YAG, Er:YAG and Er:glass are the common media which are included [15-17]. Discharge lamp is used for pumping. The diode pump is also possible to use. With typical emissions in the nearIR region, a large span of emission power is offered by this kind of laser which is having a remarkable beam quality. Pulsed operation having very short pulses can be obtained with Ti: sapphire laser.

\section{d) Fiber Lasers:}

There principle of operation is similar to solid-state lasers. In the core of the fiber the doped area is located and offers a better thermal dispersion with a unique possibility to operate in transversal single mode operation. Higher beam quality is maintained by achieving several kilowatts of emission. In medical applications, Tm doped fiber lasers are used which gives a better interaction with the soft tissues [18-20].

\section{Laser Parameters}

For a successful and efficient weld a combination of parameters are required:

\begin{tabular}{|c|l|}
\hline Laser Parameters & \multicolumn{1}{|c|}{ Importance in Welding } \\
\hline Laser peak power (P) & $\begin{array}{l}\text { - It is the density of energy delivered per unit of time (J/s or Watts). } \\
\text { Increasing the peak power overcomes thermal diffusivity and } \\
\text { reflectivity. }\end{array}$ \\
\hline
\end{tabular}

Kulshrestha R | Volume 1; Issue 1 (2020) | JDHOR-1(1)-001 | Review Article 


\begin{tabular}{|c|c|}
\hline & $\begin{array}{l}\text { - Controlled peak power }(\mathrm{P}) \text { avoid defects such as cracks and } \\
\text { porosities, depending upon the alloy. }\end{array}$ \\
\hline \multirow[b]{2}{*}{ Pulse duration } & It is the length of time of a pulse. \\
\hline & $\begin{array}{l}\text { - In alloys with good thermal conductivity (e.g. gold alloys) the } \\
\text { pulse duration must be reduced. }\end{array}$ \\
\hline \multirow[b]{4}{*}{$\begin{array}{l}\text { Pulse energy }(\mathrm{J} \text { or } \\
\mathrm{W} / \mathrm{s})\end{array}$} & - It is the relation of power $(\mathrm{kW})$ to pulse duration $\mathrm{t}(\mathrm{ms})$. \\
\hline & $\begin{array}{l}\text { - Increase in energy output is required to obtain a deep and } \\
\text { satisfactory weld. }\end{array}$ \\
\hline & $\begin{array}{l}\text { An increased risk of welding defects like porosities and surface } \\
\text { voids have been noted when the peak power is considerably } \\
\text { increased. }\end{array}$ \\
\hline & $\begin{array}{l}\text { On the contrary, the metal is subjected to excessive heat transfer } \\
\text { resulting in a reduced penetration and an incomplete weld joint } \\
\text { when power is decreased and pulse duration increased. }\end{array}$ \\
\hline \multirow[b]{2}{*}{$\begin{array}{l}\text { Pulse repetition rate } \\
(\mathrm{Hz})\end{array}$} & . It is the number of pulses delivered per second. \\
\hline & $\begin{array}{l}\text { A pulse frequency of } 1 \mathrm{~Hz} \text { to } 5 \mathrm{~Hz} \text { produces controlled welding } \\
\text { using a multi-spot process. }\end{array}$ \\
\hline \multirow[b]{2}{*}{ Pulse shape } & $\begin{array}{l}\text { It allows the control of the pulse peak power and pulse duration. } \\
\text { Fig. } 2 \text {. }\end{array}$ \\
\hline & $\begin{array}{l}\text { - The final quality and mechanical property of the material depends } \\
\text { on the appropriate selection of the pulse shape. }\end{array}$ \\
\hline \multirow[b]{2}{*}{ Focal spot size } & $\begin{array}{l}\text {. It determines the diameter of the laser beam applied to the surface } \\
\text { of the material. }\end{array}$ \\
\hline & $\begin{array}{l}\text { According to Cicila et al. best weld stability is achieved by a focal } \\
\text { spot located at the surface of the metal unlike a position above or } \\
\text { below the focalized point. }\end{array}$ \\
\hline \multirow{4}{*}{$\begin{array}{l}\text { Welding atmosphere } \\
\text { in the welding } \\
\text { chamber }\end{array}$} & $\begin{array}{l}\text { A contaminant free welding atmosphere in the laser chamber is } \\
\text { particularly important in the welding of titanium and its alloys as it } \\
\text { is highly sensitive in the presence of hydrogen, nitrogen and } \\
\text { oxygen. }\end{array}$ \\
\hline & $\begin{array}{l}\text { - A blue spot indicates oxidation in the joint }\left(\mathrm{TiO}_{2}\right) \text { and a yellow } \\
\text { spot indicates the presence of nitrogen (TiN). }\end{array}$ \\
\hline & $\begin{array}{l}\text { - Hence an argon atmosphere is essential during laser welding to } \\
\text { prevent oxidation and porosities. }\end{array}$ \\
\hline & $\begin{array}{l}\text { - The surface of the metal appears shiny gray when the flow of } \\
\text { argon is correct, approximately } 2 \text { bars flow pressure. }\end{array}$ \\
\hline
\end{tabular}

Table 2: Laser Parameters explaining its importance in welding.

- Other parameters such as the type of alloy used (precious, semi-precious, or non- precious); metal preparation; the gap between two parts; design and composition of the filler; surface characteristics of the material and the operator's skill should also be considered.

- For the finest and deepest welds appropriate selection of these parameters is important [21]. 


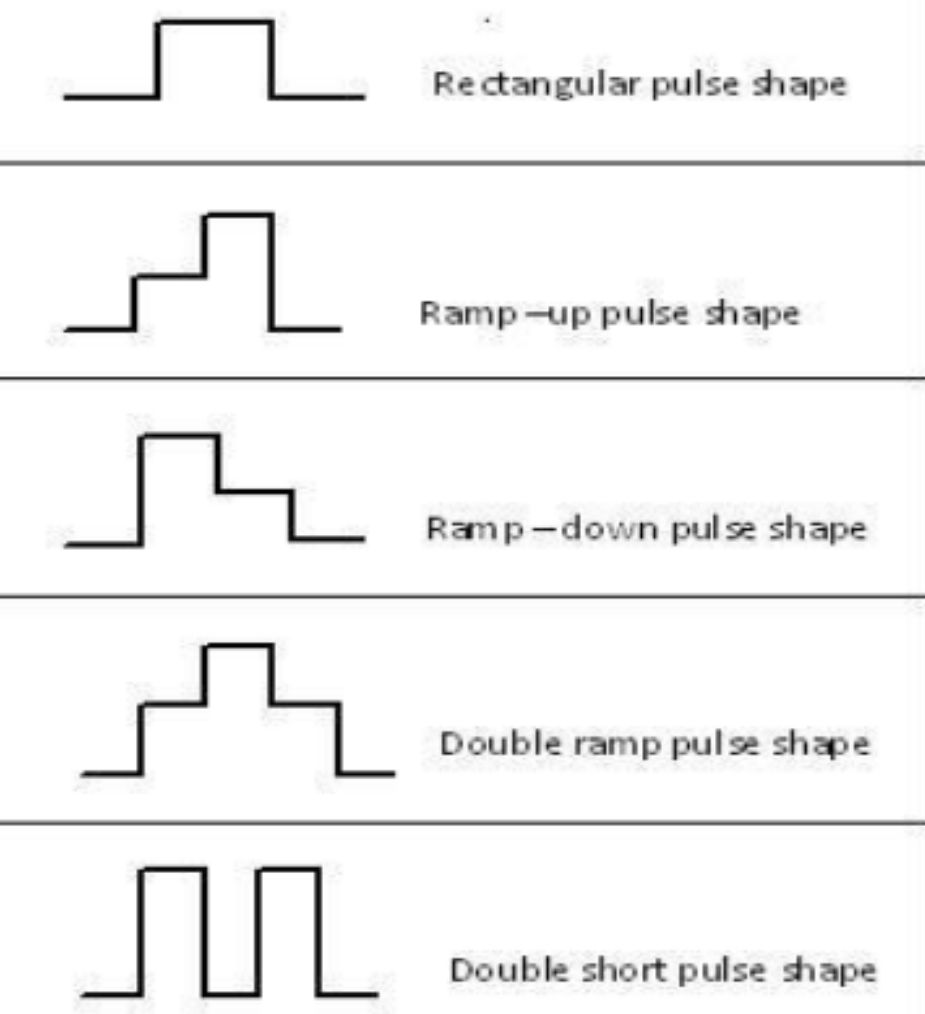

Figure 2: Pulse shape design.

\section{Laser Welding Principle}

During laser beam welding, with the help of some optical arrangement a concentrated coherent beam of monochromatic light is projected on a small spot of the prepared joint area.

Based on the reflection or mirror principle the energy from a laser beam consists of a spot of stimulated and amplified 'light' radiation. This 'light' generated from the laser head is responsible for melting the alloy. The laser head consists of a laser lamp (similar to flashlight of the camera) and a laser crystal (Nd: YAG crystal) that are arranged parallel to each other which is considered to be the 'heart' of the laser welder. The active medium hosts the garnet crystals that are stable [22]. These crystals are stimulated with neodymium or yttrium for laser beam emission. The ends of the crystal are silvered to function as mirrors internally which serve as the optical resonator, which is responsible for amplification of the beam. The laser beam emerges from a tiny hole exists at one of the end mirrors. The external energy source is the foot switch which is connected to the power supply. A laser impulse is initiated by pushing the foot switch [23-28]. This in turn causes the laser lamp to flash. Thus converting the 'electrical' energy stored in the capacitor's bank into 'light' energy. This laser emits a 1064 
nm wavelength light. The optical resonator brings the 'concentrated light energy' to the delivery unit of the laser machine where it is focused to the object to be welded with a defined energy. The parameters such as power, pulse duration, pulse energy, pulse repetition rate, pulse shape, focal spot size and the welding atmosphere in the welding chamber are controlled by control system. The optical energy focused onto the work piece is converted to heat energy, Fig. 3. The temperature generated can be optimized for effective welding [29,30]. Since most of the laser output is in the form of heat, a cooling system is required. Gas and liquid cooling systems are available, of which gas is preferred [31].

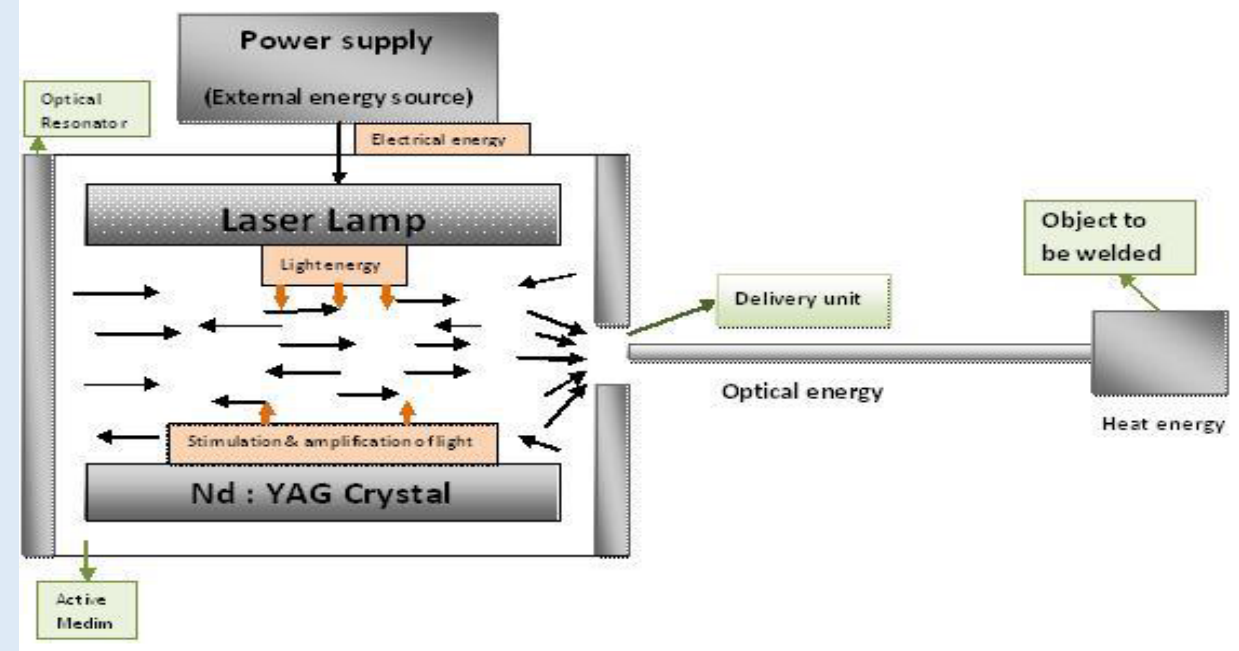

Figure 3: Laser circuit.

The most widely used laser is Nd:YAG laser $(1064 \mathrm{~nm})$ having a pulse duration range of $0.5-$ $20 \mathrm{~ms}$, operating within 1-5 kHz frequency with a pulse energy of 8-50 J. Other option in laser welding is a $\mathrm{CO}_{2}$ laser, which permits several $\mathrm{kW}$ of continuous wave operation. The $\mathrm{CO}_{2}$ laser presents some disadvantages with respect to an Nd:YAG laser, particularly related to the emission wavelength, which requires a special fiber to be delivered from the laser to the sample to be weld. Another choice in laser welding is High-Power Diode Lasers (HDPL). This family of lasers, emitting at 720-880 $\mathrm{nm}$ using algaas junction or at $940-990 \mathrm{~nm}$ using ingaas.

They consists of monolithic linear or bi-dimensional array of single laser diodes. These are typically compact and cheap. However, they have some disadvantages related to the poor beam quality and the impossibility of operating in pulsed mode. More recently, Yb-doped fiber lasers has been demonstrated for laser welding with the improvement of fiber laser technology, the

Kulshrestha R | Volume 1; Issue 1 (2020) | JDHOR-1(1)-001 | Review Article 
use of large mode area. Fiber lasers represent an alternative to Nd:YAG lasers, in particular in penetration mode welding offering a large emission power of $\mathrm{kWs}$ and the possibility to achieve high quality pulsed emission [32].

\section{Alloys for Orthodontics}

Alloys used for orthodontics should have biocompatibility for the extended period of time as they have a permanent existence in the oral environment. Nickel-chromium or cobaltchromium alloys are mostly used in orthodontics. However, the corrosion resistance capability of the alloy due to the formation of protective oxide film is correlated with their behavior in oral environments which is thermodynamically unstable. Ni-Cr alloys are also sensitive to pitting. In addition, orthodontic wires used in the bracket for bonding teeth are made of stainless steel, $\mathrm{Co}-\mathrm{Cr}$, beta-Ti and Ni-Ti. Chromium in stainless steel alloys is sufficient enough to provide corrosion protection. But if a scratch happens on the surface the will break and chloride ions containing an oral environment resists recreating the chromium oxide layer. As a result, stainless steel can be susceptible to pitting corrosion.

\section{Drawbacks of Laser Welding}

High investment, operating and maintenance costs are the main drawback of laser welding. Due to its slow welding speeds ( 25 to $250 \mathrm{~mm} / \mathrm{min}$ ), puddles may occur at the fusion point. The limitation of laser welding is only up to the depth of approximately $1.5 \mathrm{~mm}$ and additional energy only tends to create gas voids and undercuts in the work. Metals like magnesium tend to vaporize and produce severe surface voids. To overcome the minor drawbacks of laser welding, a pulsed micro electric arc welder which utilizes single pulses of tungsten gas was introduced. Unlike laser which applies 'light' energy, Tungsten Inert Gas (TIG) applies 'electric' energy. It is designed with automatic argon gas coverage of the welding spot which is delivered directly through the hand piece. It involves reduced investment costs, very compact dimensions, low weight, maintenance free and low operating costs. TIG welding with argon shielding with filler wire produced strongest and fracture resistant joints [31].

\section{Future Trends}

Laser application in dentistry has been there since the end of last century. Nevertheless, its utilization was mainly limited to specialists and researchers due to its high installation costs as well as limited control on the thermal effect of lasers on soft/hard tissues. With recent developments in laser technology and reduced expenses, orthodontists are more motivated to exploit lasers for their clinical practice. With smaller laser pulse and smaller energy, orthodontist can perform laser applications on their patients with much more safety than before. 
Laser technology is shaping the orthodontic industry and providing alternative ways for orthodontist to perform their treatments.

As described before, the greatest difficulties and problems related to the usage of laser technology for dental welding consist of the difficulty of arranging the parameters in the function of the material used, its thickness, the gap dimension and the filler alloy. Moreover, up to now, Nd:YAG laser welding devices remain bulky and require a high cost of installation and maintenance. For such reasons, the realization of small and cheap devices that are easy to use with a minimal training phase would be a great opportunity for dentists to weld metals directly in their clinics.

The employment, in the field of laser dentistry, of diode lasers, where the active medium consists of a semiconductor, has created some sort of revolution. By considering their small size and cost, the reduced size of the pumping system, the flexibility offered by the optical fiber delivery system, diode laser technology has been able to reach most of the dentists and is becoming very popular. Even if the common use of diode lasers, emitting around $810 \mathrm{~nm}$ and $940 \mathrm{~nm}$, is for soft tissue applications, due to the great absorption in hemoglobin, different wavelengths have recently been proposed.

In this context, a feasible possibility of a diode laser application for welding has emerged in the field of dentistry. In fact, diode lasers emitting at $1064 \mathrm{~nm}$, operating in $\mathrm{CW}$ operation or in chopped mode, with a high duty cycle, can be effectively taken into consideration to weld metals in orthodontics, thus representing an interesting approach to improve the use of laser welding technology. This technology, which is meant for dentistry, will continue to evolve to make itself as user friendly as possible as well as ergonomically plausible [33,34].

\section{Tips for Laser Welding Stainless Steel}

1. Stainless steel laser welds best by using the following parameter combinations:

$\cdot 215-225 \mathrm{~V}$

-3.0 MS

- 2.0-3.0 HZ

• $0.45-0.55 \varnothing$

- With basic pulse profile

2. Use of Argon gas is highly recommended when laser welding stainless steel. Improper argon flow will result in oxidizing of the metal.

3. When welding thin stainless steel parts such as a Band to a Bar, be sure to use a lower voltage, higher millisecond with the BURST PROFILE SETTING. The use of BURST profile 
will prevent the laser welder from bursting holes in the thinner band. The following parameter combinations were performed on $80 \mathrm{~J}$ weld Laser Welding System.

Note: Parameters may vary depending on the Joule energy output of the laser, flash-lamp age, and alloy surface condition.

- 9.0 MS

$\cdot 185 \mathrm{~V}$

- $3.5 \mathrm{HZ}$

$\cdot 0.55 \varnothing$

- With burst pulse profile

4. It is also necessary to fire the laser welder at an angle of about $30^{\circ}$ to $45^{\circ}$ to the seam. Firing the laser at too steep of an angle to the band can result in a hole in the band, Fig. 4.

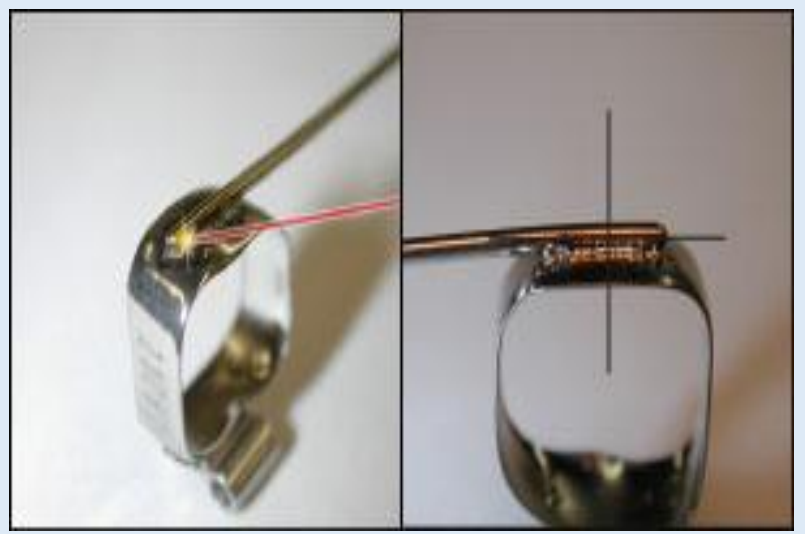

Figure 4: Showing laser welder angle.

5. When laser welding any thick to thin material, it is necessary to favor the thick material. For instance, in the case of welding a bar to a band, aim the cross hair slightly on the bar. The bulk of the laser energy will be absorbed by the thicker material (the bar). If the parameters are correct, the heat transfer will laser weld the band to the bar without bursting a hole in the band.

\section{Conclusions}

Several technologies have been employed over the past few decades to solve existing issues in dentistry. So far laser technology been the latest addition among these technologies. It clearly has made a remarkable impact and hence replaced some of the conventional techniques due to its high precision level, biocompatibility and minimal side effects. Laser welding is one of the very recent yet versatile techniques used in dentistry, which is capable of manufacturing good quality weld joints with remarkable consistency. It has offered greater advantages such as 
reasonable hardness, reduced heat affected zone and toughness over other compatible technologies available so far. Most importantly, this technology offers dental patients an intraoral surgery with limited anesthesia or without anesthesia, better comfort level, speedy recovery and aesthetic satisfaction. In light of a huge demand in laser welding technology, this paper has demonstrated the fundamentals of laser technology along with laser welding principles, a brief overview of laser welding for orthodontic materials and a laser welding phenomenon in a systematic manner. Laser welding technologies that currently available are already high-end technology. Further areas of improvement may combine the diagnostic and therapeutic laser welding technologies in one single device. There is also potential for robotic assisted dental laser welding instruments for finer laser welding operation. It will be not surprising if laser welding technology takes the place of most of the conventional alternatives by the middle of the current century.

\section{References}

1. Gordon TE, Smith DL. Laser welding of prostheses-An initial report. J Prosthet Dent. 1970;24(4):4726.

2. Apotheker H, Nishimura, I, Seerattan, C. Laser-welded vs soldered nonprecious alloy dental bridges:A comparative study. Lasers Surg Med. 1984;4(2):207-13.

3. Siegman, AE. Lasers; University Science Books: Mill Valley, CA, USA. 1986;37(208):169.

4. Goldman L, Goldman B, Lieu NV. Current laser dentistry. Lasers Surg Med. 1987;6(6):559-62.

5. Chiang S, Albright CE.The limit of joint penetration in high energy density beam welding. Weld J N Y. 1993;72:117-s.

6. Bransch H, Weckman D, Kerr H. Effects of pulse shaping on nchyag spot welds in austenitic stainless steel; US Department of Energy: Washington, DC, USA. 1994.

7. Pecas P, Henrique M, Miranda RM, Quintino L. Laser welding of low-thickness zinc-coated and uncoated carbon steel sheets. Opt Quantum Electron. 1995;27(12):1193-201.

8. Ferrance J. Metal Alloys for Orthodontics, Prosthodontics and Pediatric Dentistry. Materials in Dentistry: Principles and Applications; Lippincott Company: Philadelphia, PA, USA. 1995;281-2.

9. Tambasco J, Anthony T, Sandven O. Laser welding in the dental laboratory: An alternative to soldering. J Dent Technol. 1996;13(4):23-31.

10. Bennett WR. Background of an inversion: The first gas laser. IEEE J Sel Top Quantum Electron. 2000;6(6):869-75.

11. Li L. The advances and characteristics of high-power diode laser materials processing. Opt Lasers Eng. 2000;34(4):231-53.

12. Wataha JC. Principles of biocompatibility for dental practitioners. J Prosthet Dent. 2001;86(2):203-9.

13. Bertrand C, Le Petitcorps Y, Albingre L, Dupuis V. Prosthodontics: The laser welding technique applied to the non-precious dental alloys procedure and results. Br Dent J. 2001;190(5):255-7. 
14. Majumdar JD, Manna I. Laser processing of materials. Sadhana. 2003;28(3):495-562.

15. Anusavice KJ, Cascone P. Dental casting and soldering alloys. Phillips Sci Dent Mater. 2003;11:563620.

16. Eftekhari A. Fractal study of Ni-Cr-Mo alloy for dental applications: Effect of beryllium. Appl Surf Sci. $2003 ; 220(1): 343-8$.

17. Mosch J, Hoffmann A, Hopp M. Lightening in a bottle-state of the art joining techniques in dental technology part 1. Contin Educ. 2004;4:110-9.

18. Bertrand C, Le Petitcorps Y, Albingre L, Dupuis V. Optimization of operator and physical parameters for laser welding of dental materials. Br Dent J. 2004;196(7):413-8.

19. Solmi R, Martini D, Zanarini M, Penco SI, Rimondini L, Carinci P, et al. Interactions of fibroblasts with soldered and laser-welded joints. Biomaterials. 2004;25(4):735-40.

20. Quintino L, Costa A, Miranda R, Yapp D, Kumar V, Kong CJ. Welding with high power fiber lasers-A preliminary study. Mater Des. 2007;28(4):1231-7.

21. Bertrand C, Laplanche O, Rocca J, Le Petitcorps Y, Nammour S. Effect of the combination of different welding parameters on melting characteristics of grade 1 titanium with a pulsed $\mathrm{Nd}-\mathrm{YAG}$ laser. Lasers Med Sci. 2007;22(4):237-44.

22. Brudvik JS, Lee S, Croshaw SN, Reimers DL. Laser welding of removable partial denture frameworks. Int J Prosthodont. 2008;21(4):285-91.

23. Svelto O. Principles of Lasers; Springer: Berlin/Heidelberg, Germany. 2009.

24. Bertrand C, Poulon-Quintin A. Proposals for optimization of laser welding in prosthetic dentistry. J Prosthodont. 2010;19(1):69-76.

25. Huber G, Kränkel C, Petermann K. Solid-state lasers: Status and future. JOSA B. 2010;27(11):B93-105.

26. Brantley WA, Eliades T. Orthodontic materials: scientific and clinical aspects. Stuttgart: Thieme; 2001.

27. Da Silveira-Júnior CBD, de Castro MG, Davi LCR, das Neves FVD, Novais VR, Simamoto-Júnior PCZ. Welding techniques in dentistry. In Welding Processes; InTech: London, UK. 2012.

28. Verma SK, Maheshwari S, Singh RK. Laser in dentistry: An innovative tool in modern dental practice. Natl. J Maxillofac Surg. 2012;3(2):124.

29. Fornaini C, Merigo E, Cernavin I, Lòpez de Castro G, Vescovi P. Intraoral laser welding (ilw) in implant prosthetic dentistry: Case report. Case Rep Dent. 2012.

30. Jauregui C, Limpert J, Tünnermann A. High-power fibre lasers. Nat Photonics. 2013;7(11):861.

31. Varghese S, Bhat V, Joseph S. Laser welding of dental alloys: a systematic overview. Libyan Dent J. 2014;4:172-4.

32. Molardi C, Sun B, Yu X, Cucinotta A, Selleri S. Polarization-maintaining large mode area fiber design for 2-_m operation. IEEE Photonics Technol Lett. 2016;28(22):2483-6.

33. Maiman TH. Stimulated optical radiation in ruby. Nature. 1960;187(4736):493-4.

34. Mazumder J. Laser welding: state of the art review. Jom. 1982;34(7):16-24. 